\title{
PHYSIOLOGICAL BURDEN ON COGNITIVE PERFORMANCE OF MIDDLE MANAGERS IN MODERN ORGANIZATION: NIGERIAN EXPERIENCE
}

\author{
Ule, Prince Alamina \\ Doctoral Scholar, Department of Management, \\ Niger Delta University, Wilberforce Island, Nigeria. \\ Email: ule.alamina@gmail.com \\ Friday Ogbu Edeh \\ Department of Business Administration \\ Faculty of Management \& Social Sciences \\ Alex Ekwueme Federal University, Ebonyi State, Nigeria \\ Email: edeh.ogbu@gmail.com
}

\begin{abstract}
This study investigated the effect of physiological burden on cognitive performance of middle managers in Nigerian work organization. Data was collected from 62 middle managers in manufacturing, banking and oil firms operating within Niger Delta States, Nigeria. Data collected were subjected to multiple regression analysis and the outcome indicated that physiological burden adversely affect middle managers cognitive ability to perform assiduously in the Nigerian work environment due to burden which translate into emotional damage on their physical and mental wellbeing. The study concluded that organizations need to build structures that would enable middle managers develop self confidence in order to function amidst stressful conditions, since mental workload proves to reduce individual ability to function effectively. The study recommends that Nigerian managers should discourage coercive behaviours for improving productivity because human beings are not animals but emotional creatures that perceive negative treatment as dehumanization of their personality in the workplace.
\end{abstract}

Keyword: Cognitive Performance, Middle Managers, Psychological Burden, Stress, Workload, Work Complexity. 
Prestige International Journal of Management \& IT-Sanchayan, Vol. 8 (2), 2019, pp. 71-84, ISSN : 2277-1689 (Print), 2278 - 8441 (Online)

\section{INTRODUCTION}

Global competition and advances in modern technology have continuously caused drastic changes in the tasks and responsibilities of managers as stiff competition for scarce resources has placed increased emphasis on how organizations' need to improve in its efficiency and effectiveness (Jones \& George, 2008). Thus, top managers are encouraging their subordinates to think outside the box by taking a cross departmental view in order to identify new opportunities that will spur organizational performance (Hirte, 2018; Ule, Coker \& Idemudia, 2019) but despite these efforts to aptly implement successful strategies amidst new entries using the right measures (Floyd \& Woolridge, 1994) middle managers still perform below standard as they build structures to compensate for their weakness in macro design (Livijn, 2019) hence the attack on the roles they play in modern organization. Notwithstanding these negative attacks on the redundant nature of middle managers in modern organizations, they still play crucial roles in facilitating organizational restructuring (Balogun \& Johnson, 2004) thereby accomplishing certain organization activities geared towards renewal (Floyd \& Lane, 2000).

Although there is no denying the fact that middle managers in contemporary work organization face challenges ranging from stress related activities to physiological and psychological burden that adversely affect their cognitive ability to perform as well carryout their assigned tasks as a result of work complexities, workloads, social pursuits, work under-load that does not match employees level, etc (Blaug, Kenyon \& Lekhi, 2007; Patrick, Lee, Raha, Pillai, Gupta, Sethi, Mukeshimana, et al, 2017; Kyung, Ho, Jae, Sang, Ye, \& Hm, 2018). However, Ali, Abdiaziz and Abidqani (2013) argued that the performance and productivity of an employee in any organization is a reflection of his/her working condition which tend to influence its impact on service delivery because in a situation where such employee is exposed to stressful working conditions productivity is sure to be negatively influenced on the delivery system. Hence, Amah and Alamina (2015) in their study advocated that it is only when an employee have complete knowledge of his/her functionality (self awareness) that such employee can function effectively in organization amidst stressful working conditions and social influence and these awareness build in such individuals self confidence that will enable them have an accurate self assessment of themselves in order to be effective. In congruence with the above assertion, other scholars equally posited that the utmost desires of every organization is to increase productivity hence the need to create a healthy and stress free working environment becomes the desires of employees to assiduously perform their assigned tasks (Ibrahim, 2013; Job, 2014).

Although the gross inability of some mangers in Nigeria to effectively execute their responsibilities can be traced to low cognitive ability caused by stressful condition attached to their jobs which results from physiological burden as the work 
environment in Nigeria is clouded with uncertainties thereby forcing organizations to adopting stringent measures in order to increase productivity without recourse to the individual psychological state of mind. Perhaps, this scenario spurred Eketu (2018) to the thinking that the fear of an unpleasant consequence by Nigerian employee compels a desirable behaviour which he/she believes is capable of generating normative and continuance commitment as against affective commitment. Thus middle managers ability to function effectively amidst psychological and physiological burden and other related factors that could affect their cognitive ability to perform becomes the focal point of this paper, considering the paucity of research on the possible effect of physiological burden on cognitive performance in Nigeria.

\section{LITERATURE REVIEW}

\section{Nature and Concept of Physiological Burden}

As the workplace becomes more tensed due to increasing rate of technological advancement, managers tend to reorganize themselves in order to remain viable in their jobs. This reorganization have triggered impaired psychological work environment that have adversely generated health consequences among their workforce (Kivimaki, Vahtera, Ferrie, Hemingway \& Pentti, 2001). Surprisingly, the pathological mechanisms linking this impaired psychosocial work environment is caused by prolonged physiological stress reactions (Rikke, 2014). However, the ability of middle managers to recognize their cognitive role amidst the increasing workload creates negative effect on their health thereby increasing physiological distress, musculoskeletal disorders, fatigue and or accident that often give rise to poor quality work performance within the organization (Fournier, Montreuil, Brun, Bilodeau \& Villa, 2011).

Thus, organizations in contemporary time only pursue complex and diverse aim in order to increase their profit base (Kyung, et al., 2018) without recourse to man who perhaps experiences high work intensity due to these pressures. Volkoff, Buisset and Mardon (2010) argued that pressure experienced by employee at workplace often affect their health even at fifties and above. Hence, the mental workload of an individual in organization reduces his/her cognitive ability to function effectively which aid in affecting such individual performance due to pressure, responsibility and or job interruption (Fournier, et al., 2011; Morris, \& Leung, 2006) and such psychological burden not only hinders work performance but also have direct bearing on workers (Kyung, et al., 2018) wellbeing.

The concept "physiological burden" as introduced into workplace organization is borrowed from the clinical sciences and as such cannot be fully comprehended in management literature without recourse to its root and components thus the concept has no unified definition. Although, some scholars view it from the angle of 
Prestige International Journal of Management \& IT-Sanchayan, Vol. 8 (2), 2019, pp. 71-84, ISSN : 2277-1689 (Print), 2278 - 8441 (Online)

stress that triggers depressive behaviours felt by employees as a result of their concern for the success and or failure of their work and safety (Kyung, et al., 2018). However, Crespo-Ruiz, Rivas-Galan, Fernandez-Vega, Crespo-Ruiz and MaicasPerez (2018) additionally added that the response of the individual body to the stressors must correspond to a set of mechanism of escape whose magnitude of enrolment must depend on specific need and duration of the body.

Therefore, the physiological processes that instigate such stress must be understood in order to implement better strategies necessary for management. Hence, this study tend to define the concept as the physical, psychological and mental load employees' house in their heads in a work environment that impede on their cognitive ability to perform assigned tasks in relation to their delegated duty. This definition adopts work complexities, tasks variety, working conditions, information processing and social supports as the proxies to measure physiological burden. Although, Kyung, et al., (2018) viewed some of these variables as determinants to psychological burden which they believe are pertaining to work performed by employees in organization. Below is a model we proposed to aid upcoming scholars in this knowledge domain.

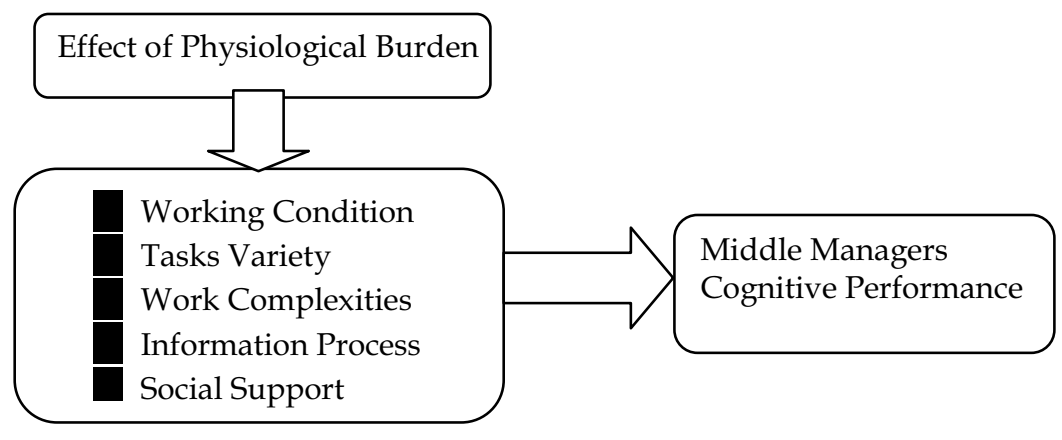

Source: Researchers' Conceptualization (2019).

\section{Middle Managers Challenge in Contemporary Era}

With the intense challenge resulting from the digital transformation taking place globally, middle managers roles are becoming blurred (Hirte, 2018) as organizations are keen in pursuing goals that will enable them remain in business. Hence, middle managers who are scheduled with the responsibility of finding solutions to achieve organizational efficiency (Jones \& George, 2008) are continually being confronted with the issues of increasing expectations of their involvement in organizational activities (Tarakci, Heyden, Floyd, Raes, \& Rouleau, 2019) thereby bringing to the fore, the role managers play since most of their activities are been substituted with modern technologies (Gratton, 2011) bringing their relevance to obsolete in contemporary era. Nevertheless, considering the 
unpredictable advancement in technology and the need to transforming organizations for increase productivity, middle managers are continuously confronted with the issues of psychological burden which adversely affect their cognitive ability to perform (Patrick, et al., 2018; Blaug, et al., 2007) effectively. This low cognitive ability elucidate the partway leading to poor physiological function such as vision, peripheral sensation and strength (Martin, Blizzard, Srikanth, Wood, Thomson, Sanders \& Callisaya, 2013) to function due to stress related burden and social pursuits.

However, considering the continual financial losses organizations incurred in recent time due to the increasing pathologies of stressors, depression and or anxiety (European Agency for Safety and Health at Work, 2015) coupled with the mental and physical consequences aggravating the risk of suffering cardiovascular diseases as well reducing the value and quality of individual work life (Backe, Scidler, Latza, Rossnagel, \& Schumann, 2012). It becomes expedient to understand the physiological processes that triggers stressors among managers in order to adopting strategies relevant for its management (Crispo-Ruiz, et al., 2018) hence, the need to prioritize strategies that could aid in improving emotional wellbeing and adaptation since emotions has both positive and negative valence (Izard, Woodburn, Finlon, Krauthamer-Ewing, Grossman, \& Seidenfeld, 2011).

\section{EMPIRICAL REVIEW IN RELATION TO THE STUDY}

With the nascent attack on the role of middle managers in contemporary organizations, Livijn (2019) examined how middle managers adapt macro design through navigating in a hierarchy. The study whose base is drawn from a case study on reorganization in a leading food production company sort to re-examine the role of middle managers in organizational design with an iterative approach that demand active involvement. The research came up with the position that lateral interaction and coordination leads to effectiveness of organization as it creates micro level elements organization needed to realize it intent behind top management strategy.

Furthermore, Hirte (2018) in a study re-evaluated the role of middle managers in order to aid them with the tool needed to succeed in a German automotive company. The study whose focus was sort to identify the role of middle managers in the implementation of a corporate incubator revealed that managers ability to influence top management and employees' was aimed at avoiding failure and resistance, thus the study becomes relevant to managers and organization who were often confronted with the challenges of transforming their firms due to unpredictable development and digitalization taking globally.

Sub and Kretzschmar (2018) conducted a study on the impact of cognitive abilities and prior knowledge on complex problem solving performance, empirical result 
Prestige International Journal of Management \& IT-Sanchayan, Vol. 8 (2), 2019, pp. 71-84, ISSN : 2277-1689 (Print), 2278 - 8441 (Online)

and a plea for ecologically valid micro world. The study was divided into two segments with the first focusing on 137 students under replicated tailoring shirt factory and the second 152 students completing a forestry scenario. The outcome of the study revealed that problem solving performance in the tailoring shop is greatly influenced by prior knowledge and reasoning. It was also found in the first category that the performance of complex problem solving is predicted by different types of system specific knowledge independently. However, the result of the second category indicates that working memory capacity has no incremental validity beyond reasoning. Based on these outcome, the researchers concluded that the performance of complex problem solving are predicted by prior knowledge and cognitive abilities as there are insufficient proof to consider complex problem solving as unique construct, therefore consider valid micro-worlds as indispensable tool for future complex problem solving research.

Kyung, et al., (2018) carried out a study on developing a basic scale for workers psychological burden from the perspective of occupational safety and health. The study while adopting a 48 item instrument distributed to a sample population of 572 workers. The outcome after a confirmatory, exploratory and correlation factor analysis conducted on the new scale indicated that work attitude, safety and healthy workload, human error, negative self assessment and organizational activity had significant correlation with stability and reliability of the model as well confirmatory factor analysis. Based on the outcome, the study concluded that psychological burden scale can measure workers psychological burden in relation to health and safety and can be applicable to small size questionnaire.

Also, Crispo-Ruiz, et al., (2018) examined executive stress management: physiological load of stress and recovery in executives on workday. The researchers recorded the heart variability rate during 48 hours from which the relationship was established between recovery quality and stress which was obtained at three different time interval (work, after wok and night). Their result revealed a negative stress balance during the workday measurement and after work but report positive at night. They therefore perceived the need to prioritize strategies in order to improve stress management among executives since; stress generated outside work homes correlates with low level of quality recovery.

Furthermore, Patrick, et al., (2017) in their study investigated the effect of sleep deprivation on cognitive and physical performance in University students. The study adopted a randomized control patter selected 64 participants with the aim of investigating the effect of night sleep deprivation on cognitive and physical performance. Hence, the outcome from the two tailed T-tests and MANOVA indicates that acute sleep deprivation have significant impact on student physical performance but not on their cognitive ability although, it has linkage to poor academic performance and physical dysfunction of the individual. 
Martins, et al., (2013) also investigated how cognitive function can modifies the effect of physiological function on the risk of multiple fall. This population based study underlined the interplay between physiological function and cognitive performance with a randomized population of 386 adults between the age ranges of $60-80$ years. Their findings indicate that adult continuous fall is as a result of their poor cognitive function due to a decline in their physical and physiological impairment.

Finally, considering the pervasive influence of individual cognitive ability to the performance and function of an organization, Deniz, Stephan and Chockalingam (2012) examined cognitive abilities and its usefulness for personnel selection using tasks performance, job satisfaction, leadership, work behaviour, job performance, contextual performance, innovation and creativity as an instrument for validation. The authors concluded that cognitive ability as an outstanding predictor should not only be used for selecting employee for a given job but rather use for the generality of workplace assessment.

However, in summary to these empirical investigation, the study contended that middle managers ability to function effectively in the contemporary work organization stem from their ability to effectively manage stressful working conditions as well adapting to strategies that could enable them overcome depression and disruptive tendencies in their cognitive ability to concentrate in executing their assigned task. Also, considering the increasing expectations of middle managers involvement towards organizational activities and processes, management of organizations' should not take for granted the exchange relationship that is expected to flourish in the interaction between the duo because why employers seek for increased productivity, employee desire in return fair treatment that could set the base for beneficial consequences (Alamina, 2017; Cropanzano \& Mitchell, 2005) since one cannot function without the other (Goulder, 1960). Thus, the need to pay specific attention to issues bordering on manager's psychological being becomes ineluctable as a joke on their emotions plays out in their work behaviour which if not given due consideration would result to negative consequences in the form of depression and even disruption in their cognitive ability to function effectively.

\section{METHODOLOGY}

The positivist philosophical perspective was employed in this study as it involves the use of questionnaire to elicit middle managers experience and opinion on the effect of physiological burden on their cognitive performance. Data was collected using Morgeson and Humphery (2006) work design questionnaire and Annuziata, Muzzatti, Lorena and Lucchini (2011) cognitive functioning self assessment scale. These questionnaires were modified to suit the study in line with the Nigerian work environment. A cross section of sixty two (62) middle managers were selected from 
Prestige International Journal of Management \& IT-Sanchayan, Vol. 8 (2), 2019, pp. 71-84, ISSN : 2277-1689 (Print), 2278 - 8441 (Online)

manufacturing firms, deposit money banks and oil companies operating in Bayelsa, Rivers, Delta and Akwa-Ibom states respectively. The reasons behind the concentration in these aforementioned states was due to the fact that the researchers believed that managers in these localities are mostly confronted with several issues ranging from frustrating work environment as a result of youth restiveness, kidnapping and perceived neglect by the government due to the activities of militancy. These factors are believed to affect the cognitive ability of managers thereby generating low performance rate as it creates lack of concentration in their operating environment.

In this study, physiological burden is measured with working condition, task variety, work complexity, information process and social support. All these variables tend to pose some kind of psychological burden on employee in their work environment as it involves a kind of mental demand on employee's that give rise to managers ability to function effectively.

\section{RESULTS}

Table 1.1 Managers demographic details

\begin{tabular}{|c|c|c|c|c|}
\hline S/no & Item & Categorization & Frequency & Percentage \\
\hline \multirow[t]{3}{*}{1.} & \multirow{3}{*}{$\begin{array}{l}\text { Managers } \\
\text { Sex }\end{array}$} & Male & 44 & $71.0 \%$ \\
\hline & & Female & 18 & $29.0 \%$ \\
\hline & & Total & 62 & $100 \%$ \\
\hline \multirow[t]{4}{*}{2.} & \multirow{4}{*}{$\begin{array}{l}\text { Managers } \\
\text { Age }\end{array}$} & 18-30 Years & 4 & $6.5 \%$ \\
\hline & & 31-40 Years & 33 & $53.2 \%$ \\
\hline & & 41 years/above & 25 & $40.3 \%$ \\
\hline & & Total & 62 & $100 \%$ \\
\hline \multirow[t]{4}{*}{3.} & \multirow{4}{*}{$\begin{array}{l}\text { Marital } \\
\text { status of } \\
\text { Managers }\end{array}$} & Single & 12 & $19.4 \%$ \\
\hline & & Married & 32 & $51.6 \%$ \\
\hline & & Others & 18 & $29.0 \%$ \\
\hline & & Total & 62 & $100 \%$ \\
\hline \multirow[t]{4}{*}{4.} & \multirow{4}{*}{$\begin{array}{l}\text { Academic } \\
\text { qualifications }\end{array}$} & NCE/Equivalent & 7 & $11.3 \%$ \\
\hline & & B.Sc/Equivalent & 39 & $62.9 \%$ \\
\hline & & $\begin{array}{ll}\begin{array}{l}\text { Above } \\
\text { degree }\end{array} & \text { first }\end{array}$ & 16 & $25.8 \%$ \\
\hline & & Total & 62 & $100 \%$ \\
\hline
\end{tabular}

As seen in the demographic table above, it indicates that out of the sixty two (62) middle managers that partake in the study $71 \%$ were male and $29 \%$ were female; $6.5 \%$ were between the ages of $18-30$ years; $53.2 \%$ were between $31-40$ years and $40.3 \%$ were between 41 years and above. Also $19.4 \%$ were single; $51.6 \%$ were married and $29.0 \%$ fall under other categories. Finally, $11.3 \%$ had NCE and its equivalent; $62.9 \%$ had B.Sc and its equivalent while $25.8 \%$ had degrees above first degree qualification. 
Physiological Burden on Cognitive Performance of Middle Managers in Modern Organization: Nigerian Experience

\begin{tabular}{|l|r|r|r|l|}
\hline \multicolumn{5}{|c|}{ Descriptive Statistics } \\
\hline Variables & No. of items & Mean & $\begin{array}{l}\text { Std. } \\
\text { Deviation }\end{array}$ & $\begin{array}{l}\text { Alpha } \\
\text { Coefficient }\end{array}$ \\
\hline Working Condition & 5 & 1.76 & .717 & .702 \\
\hline Tasks Variety & 4 & 3.03 & 1.639 & .740 \\
\hline Work Complexity & 4 & 2.11 & .977 & .849 \\
\hline Information Processing & 4 & 3.53 & 1.544 & .716 \\
\hline Social Support & 6 & 3.94 & 1.266 & .824 \\
\hline Cognitive Performance & 7 & 3.16 & 1.528 & .869 \\
\hline
\end{tabular}

The descriptive statistics shows the mean scores and standard deviations of physiological burden dimension and managers cognitive performance with social support having the highest mean value of 3.94 with a standard deviation of 1.266 followed by information process with 3.53 as mean and 1.544 as standard deviation. Also tasks variety with a mean value of 3.03 and a standard deviation of 1.639; work complexity have 2.11 as mean value and .977 as standard deviation While working condition has a mean value of 1.76 and a standard deviation of .717 and finally cognitive performance has a mean value of 3.16 and a standard deviation of 1,528 respectively.

\begin{tabular}{|l|c|c|r|r|}
\hline \multicolumn{5}{|c|}{ Model Summary } \\
\hline Model & $\mathrm{R}$ & R Square & Adjusted R Square & Std. Error of the Estimate \\
\hline 1 & $.738^{\mathrm{a}}$ & .545 & .504 & 1.076 \\
\hline $\begin{array}{l}\text { a. Predictors: (Constant),Social support, Task variety, Information process, Working } \\
\text { conditions, Work complexity }\end{array}$
\end{tabular}

\section{ANOVA $^{\mathrm{a}}$}

\begin{tabular}{|l|l|r|r|r|c|c|}
\hline \multicolumn{2}{|l|}{ Model } & Sum of Squares & df & Mean Square & F & Sig. \\
\hline \multirow{3}{*}{1} & Regression & 77.532 & 5 & 15.506 & 13.389 & $.000^{\mathrm{b}}$ \\
\cline { 2 - 7 } & Residual & 64.855 & 56 & 1.158 & & \\
\cline { 2 - 7 } & Total & 142.387 & 61 & & & \\
\hline
\end{tabular}

a. Dependent Variable Cognitive performance

b. Predictors: (Constant), Social support, Task variety, Information process, Working conditions, Work complexity

\begin{tabular}{|c|c|c|c|c|c|c|c|c|}
\hline & & & & Coefficients & & & & \\
\hline & odel & $\begin{array}{r}\text { Unstar } \\
\text { Coeff }\end{array}$ & $\begin{array}{l}\text { ardized } \\
\text { ients }\end{array}$ & $\begin{array}{l}\text { Standardized } \\
\text { Coefficients }\end{array}$ & $t$ & Sig. & $\begin{array}{r}95.0 \% \mathrm{C} \\
\text { Inter }\end{array}$ & $\begin{array}{l}\text { nfidence } \\
1 \text { for B }\end{array}$ \\
\hline & & B & $\begin{array}{l}\text { Std. } \\
\text { Error }\end{array}$ & Beta & & & $\begin{array}{l}\text { Lower } \\
\text { Bound }\end{array}$ & $\begin{array}{l}\text { Upper } \\
\text { Bound }\end{array}$ \\
\hline & (Constant) & 2.697 & 1.251 & & 2.156 & .035 & .191 & 5.203 \\
\hline & $\begin{array}{l}\text { Work } \\
\text { condition }\end{array}$ & -1.018 & .430 & -.478 & -2.366 & .021 & -1.880 & -.156 \\
\hline & Task variety & -.149 & .113 & -.160 & -1.320 & .192 & -.374 & .077 \\
\hline 1 & $\begin{array}{l}\text { Work } \\
\text { complexity }\end{array}$ & . 198 & .340 & .127 & .583 & .562 & -.482 & .879 \\
\hline & $\begin{array}{l}\text { Information } \\
\text { process }\end{array}$ & .228 & .129 & 231 & 1.773 & .082 & -.030 & .486 \\
\hline & $\begin{array}{l}\text { Social } \\
\text { support }\end{array}$ & .376 & .179 & .312 & 2.096 & .041 & .017 & .736 \\
\hline
\end{tabular}

a. Dependent Variable: Cognitive performance 
Prestige International Journal of Management \& IT-Sanchayan, Vol. 8 (2), 2019, pp. 71-84, ISSN : 2277-1689 (Print), 2278 - 8441 (Online)

A multiple regression analysis was conducted to examine the effect of physiological burden on cognitive performance of middle managers in the contemporary Nigerian work environment. The result as indicated in the ANOVA shows the fitted regression equation with $\mathrm{F}$ value of 13.389 indicating the goodness fit of the model. However, all physiological burden variables puts together statistically predict middle managers cognitive performance $f(5,61)=13.389, p<0.05$ and $R^{2}=0.545$. This outcome reveals that $55 \%$ of middle managers cognitive performance in the Nigerian work environment can be explained by physiological burden they encounters while the remaining $45 \%$ cannot be accounted for by the dimensions of physiological burden as adopted by this study and therefore considered as error term.

The independent result of this regression analysis indicates that work complexity, information process among middle managers and social support given to managers all significantly predict and influence the variance in their cognitive performance at $95 \%$ confidential level with social support having a beta value, $\beta=.312$ and $t=2.096$ followed by information process with a beta value, $\beta=.231$ and $t=1.773$ and work complexity with a beta value, $\beta=.127$ and $t=.583$ while working condition and tasks variety negatively predict the change in cognitive performance with working condition having a beta value, $\beta=.-.478$ and $t=-2.366$ and tasks variety having beta value, $\beta=-.160$ and $t=-1.320$ respectively.

\section{DISCUSSION OF RESULTS}

The study made an attempt to investigate the effect of physiological burden on cognitive performance of middle managers in modern organization with specific interest in the Nigerian work environment. The general outcome from the analysis revealed that physiological burden predicts middle managers cognitive performance in the Nigerian work environment.

This outcome is not surprising as it has been noticed that the Nigerian work environment is always plagued with countless challenges such that middle managers cognitive ability to function is impaired with several factors ranging from stress related outcomes to work pressure, work overload and or work strains, etc. In line with scholarly positions, Patrick, et al., (2017); Martin, et al., (2013); Blaug, et al., (2007) opines that physiological burden adversely affect middle managers cognitive ability to perform effectively because these burden in most cases translate into emotional damage on middle managers mental and physical wellbeing hence, impaired on their cognitive ability to even recognize basic responsibility as well as vision and peripheral sensation talk more of performance. This position perhaps instigate Amah and Alamina (2015) argument that organizations can only increase productivity when employees' in their working environment ably understand their selves amidst stressful working conditions and social influences in order to 
Physiological Burden on Cognitive Performance of Middle Managers in Modern Organization: Nigerian Experience

function effectively due to the fact that these understanding would enable such individual to build in self confident to withstand external pressure. Thus the increasing pathologies that trigger stress related symptoms in organizations can be curbed or reduced in order that middle managers could add value to organizations. It is equally pertinent to note that social support, information process and work complexities positively explains middle managers cognitive performance while on the contrary, working condition and tasks variety negatively contribute to the change in middle managers cognitive performance.

The implication in these assumptions indicate that if organizations support middle managers in executing their responsibilities through information sharing with guided activities towards work related outcome, middle managers in these environment would be strengthened to face the increasing expectation of their involvement towards organizational processes, even when the working conditions and tasks of such activity seems not to be favourable. Although, the argument here is in opposite direction with the work of Ali, et al., (2013) who posits that employee's performance and increased productivity in an organization is the reflection of an individual working condition which they believe have direct bearing on service delivery because when such employee is exposed to stressful working conditions, the outcome has negative influence on his/her cognitive senses. These stressful working conditions create a sense of poor cognitive function irrespective of the work environment as it adversely affect other physiological factors (Martin, et al., 2013) that hinders performances among organizations.

\section{CONCLUSION AND RECOMMENDATION}

The increasing quest for the reorganization of middle managers role in order to remain in business as well maintain their jobs is not a new phenomenon in the Nigerian context, considering the increasing rate of technological advancement globally. In fact, middle managers have been identified to facing confrontations with issues of increasing expectations of their role involvement in organizational process on daily bases thereby increasing managers' physiological burden on cognitive performance. Thus, middle managers tend to build in structures to compensate for their weaknesses since most organizations no longer pay attention to their wellbeing rather on how to increase productivity without recourse to managers exerted effort towards achieving this productivity.

The study therefore, conclude that since stress is relative to man's individual and social life, it becomes a prerogative for organizations and employers of labour in the Nigerian work organization to build in structures that would enable middle managers to develop self confidence in order to function amidst stressful working conditions because increase mental workload reduces individual cognitive ability to function effectively. In line with the conclusion, the study recommends that 
Nigerian managers should discourage coercive acts of increasing productivity because human beings are not animals but emotional beings that perceive negative treatment as a call to dehumanization of their personality in the workplace therefore, the need to support middle manager morally and emotionally become ineluctable.

\section{REFERENCES}

- Alamina, P.U. (2017). Managerial emotional intelligence and workers productivity: The Nigerian experience. International Journal of Advanced Academic Research - Social and Management Sciences, 3(5), $43-56$.

- Ali, Y. S. A., Abdiaziz, A. A., \& Abidqani, A. A. (2013). Working conditions and employees' productivity in manufacturing companies in Sub-Saharan African context: case of Somalia. Educational Research International, 2(2), 67-78.

- Amah, E., \& Alamina, P. U. (2015). Supervisors, self awareness and workers productivity in selected hotels in Bayelsa State, Nigeria. The International Journal of Business and Management, 3(12), 129-134.

- Annuziata, M. A., Muzzatti, B., Lorena, G., \& Lucchini, G. (2011). Cognitive functioning self assessment scale (CFSS): preliminary psychometric data. Psychology Health and Medicine, 17(2), 207 - 212.

- Backe, E. M., Seidler, A., Latza, U., Rossnagel, K. \& Schumann, B. (2012). The role of psychosocial stress at work for the development of cardiovascular diseases: a systematic review", International Archives of Occupational and Environmental Health, 85(1), 67-79.

- Balogun J., \& Johnson, G. (2004). Organizational restructuring and middle manager sense making. Academy of Management Journal, 47(4), 523 - 549.

- Blaug, R., Kenyon, A., \& Lekhi, R. (2007). Stress at work. The Work Foundation.

- Crespo-Ruiz, B., Rivas-Galan, S., Fernandez-Vega, C., Crespo-Ruiz, C., \& MaicasPerez, L. (2018). Executive stress management: physiological load of stress and recovery in executives on workdays. International Journal of Environmental Research and Public Health, 15, 2-14. Doi:10.3390/ijerph15122847

- Cropanzano, R. \& Mitchell, S. M. (2005). Social exchange theory: An Interdisciplinary review: Journal of Management, 31(6), 877-900.

- Deniz, S. O., Stephan, D., \& Chockalingam, V. (2012). Cognitive abilities. Doi:10.1093/oxfordhb/9780199732579.013.0010 (retrieved on $18^{\text {th }}$ September, 2019) from https:/ / www.researchgate.net/publication/285935869.

- Eketu, C.A. (2018). Interpretive paradigm on the use of fear as workers coercive motivation. Academic of Social Science Journal, 3(5), 1178 - 1181.

- European Agency for Safety and Health at Work (2015). Available online: https://osha.europa.eu/en/tools-and-publications/blog (accessed 10/08/19)

- Floyd, S. W., \& Woolridge, B. (1994). Dinosaurs or dynamos? Recognizing middle management's strategic role. Academy of Management Executive, 8(4), 47 - 57.

- Floyd, S. W., \& Lane, P. J. (2000). Strategizing throughout the organization: Managing role conflict in strategic renewal. Academy of Management Review, 25, 154 177. 
- Fournier, P. S., Montreuil, S., Brun, J. P., Bilodeau, C., \& Villa, J. (2011). Exploratory study to identify workload factors that have an impact on health and safety: a case study in the service sector. (RSST Report R-701).

- Gouldner, A. (1960). The Norms of Reciprocity. American Sociological Reviews, 25(2), $161-178$.

- Gratton, L. (2011). The end of the middle manager. Harvard Business Review, page 89.

- Hirte, R. (2018). The role of middle managers in the implementation of a corporate incubator: a case study in the automotive sector. Technology Innovation Management Review, 8(7), $31-39$.

- Ibrahim, C. (2013). Motivation and its impact on labour productivity at hotel business. A conceptual study. International Journal of New Trends in Arts Sports $\mathcal{E}$ Science Education, 2(1), 70 - 79.

- Izard, C.E., Woodburn, E.M., Finlon, K J., Krauthamer-Ewing, E.S., Grossman, S. R., \& Seidenfeld, A. (2011). Emotion knowledge, emotion utilization and emotion regulation. Emotion Review, 3(1), 44-52.

- Job, A. E. (2014). Occupational stress and employees productivity in the Workplace. International Journal of Scientific Research Education, 7(2), 157 - 165.

- Jones, R. G. \& George, M. J. (2008). Contemporary Management. $5^{\text {th }}$ edition. McGraw Hill Irwin. New York.

- Kivimaki, M., Vahtera, J., Ferrie, J. E., Hemingway, H., \& Pentti, J. (2001). Organizational downsizing and musculoskeletal problems in employees: a prospective study. Occupational and Environmental Medicine, 58(12), 811-817.

- Kyung, W. O., Ho, C, L., Jae, H. P., Sang, G. P., Ye, J. P., \& Hm, H. C. (2018). Developing a basic scale for workers psychological burden from the perspective of occupational safety and health. Safety and Health at Work, 9, 224-231.

- Livijn, M. (2019). Navigating in a hierarchy: how middle managers adapt macro design. Journal oforganization Design, 8(7), 1-27.

- Martin, K. L., Blizzard, L., Srikanth, V. K., Wood, A., Thomson, R., Sanders, L. M., \& Callisaya, M. L. (2013). Cognitive function modifies the effect of physiological function on the risk of multiple falls: a population based study. Journals of Gerontology A Biol Sci Med Sci, 68(9), 1091 - 1097.

- Morgeson, F. P., \& Humphery, S E. (2006). The work design questionnaire: Developing and validating a comprehensive measure for assessing job design and the nature of work. Journal of Applied Psychology, 91,1321 - 1339.

- Morris, C. H., \& Leung, Y. K. (2006). Pilot mental workload: How well do pilots really perform? Ergonomics, 49(15), 1581 - 1596.

- Patrick, Y., Lee, A., Raha, O., Pillai, K., Gupta, S., Sethi, S., Mukeshimana, F., Gerard, L., Moghal, M. U., Saleh, S. N., Smith, S. F., Morrell, M. J., \& Moss, J. (2017). Effect of sleep deprivation on cognitive and physical performance in university students. Sleep Biol. Rhythms, 15, 217-225.

- Rikke, H.C. (2014). Physiological stress reactions: Interventions of psychosocial work environment - distress and rehabilitation. PhD Thesis submitted to the Graduate School at the Faculty of Health and Medical Sciences, University of Copenhagen. 
Prestige International Journal of Management \& IT-Sanchayan, Vol. 8 (2), 2019, pp. 71-84, ISSN : 2277-1689 (Print), 2278 - 8441 (Online)

- Sub, H., \& Kretzschmar, A. (2018). Impact of cognitive abilities and prior knowledge on complex problem solving performance - empirical results and a plea for ecologically valid micro-worlds. Frontiers in Psychology, 9,626, 1-22.

- Tarakci, M., Heyden, M. L. M., Floyd, S. W., Raes, A., \& Rouleau, L. (2019). (Re)Conceptualizing middle managers' roles in modern organization. Journal of Management Studies, Special Issue Call for Papers

- Ule, P. A., Coker, P. R., \& Idemudia, S. A. (2019). Entrepreneurship and strategic management relationship and distinctiveness: the germane of a new discipline. International Journal of Recent Innovations in Academic Research, 3(3), 142 - 153.

- Volkoff, S., Buisset, C., \& Mardon, C. (2010). Does intense time pressure at work make older employees more vulnerable? A statistical analysis based on a French survey. ApplErgon, 41(6), 754-762. 